\title{
Determining Risk Factors of Epilepsy in Children with Cerebral Palsy: A Retrospective Study
}

\author{
(D) Ferda Gürkan1, (1) Sarenur Gökben2, (1) Hepsen Mine Serin2, (1) Sanem Yılmaz2, (1) Gül Aktan2, \\ (1) Hasan Tekgül2
}

${ }^{1}$ Ege University Faculty of Medicine, Department of Pediatrics, İzmir, Turkey

2Ege University Faculty of Medicine, Department of Pediatrics, Division of Child Neurology, İzmir, Turkey

\begin{abstract}
Aim: The aim of this study is to determine the risk factors of epilepsy development in children with cerebral palsy.

Materials and Methods: Data of 234 cerebral palsy patients treated at Ege University Pediatrics Department, Child Neurology Division between January 2008 and December 2015 were evaluated retrospectively. All patients were classified into two groups; Group I: cerebral palsy without epilepsy $(n=116)$ and Group II: cerebral palsy with epilepsy $(n=118)$. The clinical and laboratory findings of the groups were compared to each other, a $p$ value of less than 0.05 was considered as statistically significant.

Results: There was no significant difference between the two groups in terms of gender, gestastional age, birth type, birth weight, risk factors for cerebral palsy development (pre-/peri-/postnatal), duration of neonatal intensive care stay and the need for mechanical ventilation ( $p>0.05)$. The risk factors of epilepsy were determined as the following; the presence of neonatal convulsions, focal clonic and generalized tonic neonatal seizures, an abnormal baseline rhythm on neonatal electroencephalography (EEG), discharge from neonatal intensive care unit with at least one antiepileptic drug, spastic bilateral (tetraplegic) cerebral palsy, epileptic activity on the sixth month EEG, abnormal cranial magnetic resonance imaging findings, mental retardation, microcephaly and visual problems.

Conclusion: Epilepsy is a common problem in children with cerebral palsy. Therefore, cases of cerebral palsy, especially those with the determined risk factors should be closely monitored for epilepsy in order to ensure a timely diagnosis and proper treatment.

Keywords: Cerebral palsy, epilepsy, risk factor
\end{abstract}

\section{Introduction}

Cerebral palsy (CP) is a non-progressive, mainly postural, motor impairment disorder of the developing brain which develops due to various causes during the intrauterine period, or shortly after birth. The incidence of CP has been reported to be 2 to 5 per 1.000 live births (1). In a study conducted in Turkey, the prevalence of CP was reported to be 4.4 per 1.000 live births (2). Epilepsy is common in children with CP with a varying rate of 15 to $60 \%$ (3-5). However, there are few studies which extensively investigated this topic in the literature. In the present study, we aimed to identify the risk factors for epilepsy development in children with CP.

\section{Materials and Methods}

In this study, the data of $234 \mathrm{CP}$ patients treated at Ege University Faculty of Medicine, Department of Pediatrics, Division of Child Neurology between January 2008 and December 2015 were evaluated retrospectively. The diagnosis of CP was based on the definition of motor dysfunction caused by a non-progressive, static lesion in the developing brain (6). The patients were classified according to their gestational age (GA) and birthweight (BW) for GA (7). Newborns who were born prior to 37 weeks and between 37 and 42 weeks were accepted as preterm and term babies, 
respectively. Newborns weighing less than $10^{\text {th }}$ percentile and weighing between $10^{\text {th }}$ and $90^{\text {th }}$ percentile were defined as small for GA and appropriate for GA (AGA) respectively. Pre-/ peri-/postnatal risk factors for CP were as follows:

\section{Prenatal Risk Factors}

- Intrauterine infections

- Central nervous system (CNS) malformations

- Genetic syndromes

- Placental insufficiency

- Teratogenic factors

- Multiple pregnancy

- Maternal chronic illness

Perinatal Risk Factors

- Premature birth

- Complications during birth

- Maternal infection

- Meconium aspiration syndrome

- Perinatal asphyxia

- Kernicterus

Postnatal Risk Factors

- Sepsis

- Intracranial hemorrhage

- Ischemic stroke

- Hypoglycemia

- Other metabolic disorders

The duration of neonatal intensive care unit (NICU) stay and neonatal convulsions classified according to the Volpe classification were recorded (8). The electroencephalogram (EEG) during the neonatal period was evaluated in terms of background and epileptic activity. The background activity was accepted as abnormal if the expected characteristics of the post-conceptional age were absent or diffusely decreased or asymmetric in amplitude. Cranial magnetic resonance imaging (MRI) findings were also evaluated. The patients who were discharged from NICU with antiepileptic drug therapy were noted. The type of CP was assessed according to the Surveillance of CP in Europe classification (9). Spastic bilateral type CP patients were also divided into tetraplegic and diplegic according to the predominant involvement of the upper and lower limbs (10). Accompanying problems such as mental retardation, microcephaly, vision problems and hearing problems were also recorded. Epilepsy was defined as $\geq 2$ afebrile seizures occurring beyond the neonatal period (11).

All patients were classified into two groups (Group I: CP without epilepsy, Group II: CP with epilepsy). Seizure and epileptic syndromes were evaluated according to the International League Against Epilepsy classification (12). In addition, EEG findings at six months, antiepileptic drug use and duration, response to therapy and final EEGs of Group II were recorded. The study was approved by the Ege University Local Ethics Committee under the reference number 16-3/3 and was conducted in accordance with the principles of the Declaration of Helsinki.

\section{Statistical Analysis}

Statistical analysis was performed using the SPSS Statistics version 23 software (IBM Corp., Armonk, NY, USA). The chi-square test and Fisher's exact test, where appropriate, were used to compare categorical variables. The odds ratio $(\mathrm{OR})$ with confidence intervals $(\mathrm{Cl})$ was calculated to evaluate the effects on prognosis. Independent two-group t-test and Mann-Whitney $U$ test were used to compare the numerical variables. Multiple logistic regression analyses were used to identify the factors affecting prognosis using variables which were significant in the univariate analysis or were below a $p$

Table I. Demographic and clinical characteristics of two groups

\begin{tabular}{|c|c|c|c|}
\hline & $\begin{array}{l}\text { Group I } \\
(n=116)\end{array}$ & $\begin{array}{l}\text { Group II } \\
(n=118)\end{array}$ & $\begin{array}{l}\mathrm{p} \\
\text { value }\end{array}$ \\
\hline Current age, months, (SD) & $109.62(59.65)$ & $119.94(70.19)$ & 0.22 \\
\hline Sex (female/male) & $46 / 70$ & $50 / 68$ & 0.673 \\
\hline Parental consanguinity & 20 & 23 & 0.871 \\
\hline $\begin{array}{l}\text { Seizure in first-degree } \\
\text { relatives }\end{array}$ & 5 & 8 & 0.709 \\
\hline Mode of delivery & - & - & 0.240 \\
\hline Normal vaginal delivery & 48 & 49 & \\
\hline Caesarian section & 63 & 68 & \\
\hline Instrumental delivery & 5 & 1 & \\
\hline Gestational age, weeks, (SD) & $35.89(4.75)$ & $36.95(4.03)$ & 0.111 \\
\hline Birth weight, $g$, (SD) & $2565(1010)$ & $2725(944)$ & 0.248 \\
\hline Prenatal risk factors* & 27 & 31 & 0.596 \\
\hline Perinatal risk factors* & 72 & 71 & 0.766 \\
\hline Postnatal risk factors* & 24 & 20 & 0.464 \\
\hline Stay in NICU & 74 & 62 & 0.081 \\
\hline Duration in NICU, day, (SD) & $32.7(26.82)$ & $32.08(24.62)$ & 0.783 \\
\hline $\begin{array}{l}\text { Need for mechanical } \\
\text { ventilation }\end{array}$ & 39 & 35 & 0.515 \\
\hline Neonatal convulsion & 20 & 45 & 0.000 \\
\hline \multicolumn{4}{|l|}{ Cerebral palsy type } \\
\hline $\begin{array}{l}\text { - Spastic bilateral } \\
\text { (tetraplegic) }\end{array}$ & 42 & 66 & 0.002 \\
\hline - Spastic bilateral (diplegic) & 38 & 20 & 0.005 \\
\hline - Spastic unilateral & 32 & 29 & 0.6 \\
\hline - Dyskinetic & 4 & 3 & 0.5 \\
\hline
\end{tabular}

*Patients with more than one risk factor, NICU: Neonatal intensive care unit, SD: Standard deviation 
value of 0.1. A p value of 0.05 was considered statistically significant.

\section{Results}

Group I (CP without epilepsy) and Group II (CP with epilepsy) consisted of 116 (49.6\%) and 118 patients (50.4\%) respectively. The demographic and clinical characteristics of both groups are shown in Table I.

In both groups, the rate of prematurity was similar $39.7 \%$ vs $32.2 \%)(p=0.235)$. The majority of all patients were AGA infants $(77.8 \%, \mathrm{n}=182)$. There was no statistically significant difference in the BW for $\mathrm{GA}$ between the two groups ( $p=0.817$ ). In all patients, there was at least one risk factor for $\mathrm{CP}$ development. Among the risk factors, perinatal risk factors were the most common ( $n=143,61.1 \%)$, followed by prenatal risk factors ( $n=58,24.8 \%)$. The frequencies of pre-, peri- and postnatal risk factors were similar in both groups ( $p>0.05$ ). A history of NICU hospitalization was reported in a total of 136 patients $(58.1 \%)$ with a similar rate in both groups. There was no significant difference between the groups in terms of the length of stay in the NICU and the need for mechanical ventilation. Neonatal convulsion was observed in 20 and 45 patients in Group I and Group II respectively (17.2 vs 38.1\%). A history of neonatal convulsion was found to be a significant risk factor for epilepsy [OR=2.959, 95\% Cl (1.610-5.437), $p=0.000]$. The seizure type was also important. Focal clonic and generalized tonic seizures were identified as significant risk factors for the development of epilepsy [OR values, $5.918,95 \% \mathrm{Cl}(1.241-28.221), p=0.026$ and $11.8,95 \% \mathrm{Cl}(1.466$ 95.526), $p=0.02]$. Thirty-four of $65 \mathrm{EEGs}$ recorded during the neonatal period were available and they were re-evaluated by the author, S.G. Abnormal background activity was observed in 4 and 11 patients in Group I and Group II respectively. Its presence increased the risk of epilepsy by six times in patients with $\mathrm{CP}[\mathrm{OR}=5.958,95 \% \mathrm{Cl}(1.332-26.662), \mathrm{p}=0.02]$.

The most frequent abnormality of the EEGs recorded in the neonatal period was focal or multifocal epileptic activity $(n=20,58.8 \%)$. This ratio was identical in both groups (10 vs 10), as well as the generalized epileptic activity (3 vs 3 ). The suppression burst pattern was only seen in three patients $(17.6 \%)$ in Group II. There were no statistically significant differences in the epileptic activity on neonatal EEG between the groups $(p=0.291)$.

Cranial MRI scans were obtained within the neonatal period in 40 patients, and all of them revealed abnormal findings. Hydrocephalus, cerebral abnormalities, intracranial hemorrhage and periventricular leukomalacia were the most frequent findings in order of occurence. There were no significant differences in the neuroimaging findings between the two groups ( $p>0.05)$. Fifty-eight of 65 patients (89.2\%) with neonatal convulsion were discharged from the NICU with at least one antiepileptic drug. The number of these patients was 16 and 42 in Group I and Group II respectively, indicating a statistically significant difference [OR $=3.454,95 \% \mathrm{Cl}$ (1.8066.606), $p=0.000]$. Spastic bilateral (tetraplegic) type CP was the most common type of $C P$, and the incidence was significantly higher in Group II ( $p=0.011)$. The second most common type was spastic unilateral CP. The spastic bilateral (diplegic) type was found in 58 patients and the frequency was significantly higher in Group I ( 38 vs $20, p=0.01$ ). The risk of epilepsy in spastic bilateral (tetraplegic) CP patients was found to be 2.986 times higher than other CP types [95\% Cl (1.535-5.808), $p=0.001]$. Control EEGs at six months were performed on 53 of the 65 patients with neonatal seizures (Group I: $n=18$, Group II: $n=35$ ). The background activity was normal in $94.4 \%$ and $68.5 \%$ patients in Group I and Group II respectively $(p=0.12)$. Focal or multifocal epileptic activity on EEC at six months was observed in 3 of 18 patients (16.6\%) in Group I and 17 of 35 patients in Group II (48.5\%). Generalized epileptic activity and hypsarrhythmia were found in 4 and 6 patients in Group II respectively. At six months, the presence of epileptic activity on EEG was found to increase the risk of epilepsy by 16.875 fold [95\% Cl (3.882-73.347), $p=0.000]$. The patients were first evaluated at the child neurology clinic between 1 and 209 months of age (mean age: 8.7 months). The overall median epilepsy onset age was 6 months (1 to 174 months). The median epilepsy onset age was 3 months, 8.5 months, 24.5 months and 33 months in the patients with spastic bilateral (tetraplegia), spastic unilateral, spastic bilateral (diplegia) and dyskinetic type CP respectively. However, it did not reach statistical significance $(p=0.069)$. Generalized seizures $(46.6 \%)$ were the most common type of seizures, followed by focal and secondary generalized seizures (39\%). Infantile spasm was observed in nine patients (10.1\%). Febrile seizure was present in one patient, while both febrile and afebrile seizures were present in seven patients $(6 \%)$. West syndrome was identified in nine patients $(7.6 \%)$ and two of these progressed into LennoxGastaut syndrome during follow-up. Final EEGs of Group II revealed normal background activity in 83 patients (70.3\%) and decreased activity in 30 patients (25.4\%). In five patients (4.3\%), amplitude asymmetry was observed. Epileptic activity was seen in all but 24 patients. Focal or multifocal epileptic activity was the most common finding ( $n=66,55.9 \%$ ). Generalized epileptic activity and hypsarrhythmia were found in $19(16.1 \%)$ and 9 patients (7.7\%) respectively. In Group II, antiepileptic treatment was discontinued in 9 patients. The remaining patients continued to use antiepileptic drugs either as mono- or combined therapy ( $47.5 \%$ vs $24.6 \%$ ). Drug resistant epilepsy was observed in 24 patients (20.3\%).

In 209 patients, cranial MRI was performed at the end of the first year of life. The frequency of abnormal findings was similar in the two groups ( $86.3 \%$ vs $93.5 \% ; p=0.084$ ). Periventricular leukomalacia was the most frequent finding 
in both groups ( $41.2 \%$ vs $52.3 \% ; p=0.219)$. The rate of cerebral atrophy, cerebral abnormality, and hydrocephalus were significantly higher in Group II. These findings were also significantly related to epilepsy development in CP patients. The OR values for cerebral atrophy, cerebral abnormality and hydrocephalus were found to be $4.545,4.000$ and 4.889 respectively [95\% Cl (1.437-14.378), $\mathrm{p}=0.01,95 \% \mathrm{Cl}$ (1.27712528), $p=0.01,95 \% \mathrm{Cl}(1.482-16.128), p=0.009]$. Intracranial hemorrhage and ischemic changes were observed in 10 patients (9.8\%) in Group I and in 5 patients (4.7\%) in Group II. However, the difference was not statistically significant $(p=0.062)$. In addition, mental retardation (65\%) was the most common accompanying problem in CP patients, which affected $50 \%$ and $79.7 \%$ of the patients in Group I and Group II respectively $(p=0.000)$. The presence of mental retardation was found to increase the risk of epilepsy by 3.9 times [95\% $\mathrm{Cl}(2.199-6.977), \mathrm{p}=0.000]$. Microcephaly was found in $43.6 \%$ among all patients including $27.6 \%$ of the patients in Group I and $68.6 \%$ of the patients in Group II. In the patients with microcephaly, the risk of epilepsy increased 3.828 fold [95\% $\mathrm{Cl}(2.212-6.627), \mathrm{p}=0.000]$. Furthermore, visual problems (i.e., refractive error, strabismus, reduced vision) were detected in 45 of the patients (19.2\%). In these patients, the risk of epilepsy increased about 2.948 fold [95\% Cl (1.456-5.969), $p=0.003]$. Risk factors for epilepy in children with CP are shown in Table II.

\section{Discussion}

In our study population, the prevalence of epilepsy was $50 \%$, which is consistent with the literature data $(3,4,13-17)$. There was no significant difference between $\mathrm{CP}$ and $\mathrm{CP}$ with epilepsy groups in terms of gender, parental consanguinity, family history of epilepsy and birth type ( $p>0.05)$. In the present study, there were no significant differences in terms of GA and prematurity between Group I and Group II. Although Zelnik et al. (15) reported that epilepsy frequency was higher in term infants with CP similar to our study, no correlation was found between GA and the risk of epilepsy in other studies (17). In addition, there was no significant difference in terms of BW for GA between the groups in our study $(p=0.817)$. Similar results were previously reported in the literature (15). Also, there were no significant differences in the risk factors related to the development of $\mathrm{CP}$ between the groups ( $p>0.05)$. However, Carlsson et al. (5) reported that epilepsy was seen more frequently in patients with CNS infections, CNS malformation and gray matter injury. Similar to our results, Sellier et al. (18) found no significant association between the risk of epilepsy and the need for hospitalization and treatment with mechanical ventilation in the NICU. Review of the literature revealed several studies indicating that neonatal convulsion was a siginificant risk factor for epilepsy $(15,17,19-21)$. In the present study, we also found a similar relationship. Compared to those without

Table II. Risk factors for epilepy development in children with cerebral palsy

\begin{tabular}{|c|c|c|c|c|c|}
\hline Risk factor & Grup I (n=116) & Grup II $(n=118)$ & Odds ratio & $95 \%$ Confidence interval & $p$ value \\
\hline Neonatal convulsion & 20 & 45 & 2.959 & $1.610,5.437$ & 0.000 \\
\hline Neonatal focal clonic seizure & 2 & 8 & 5.918 & $1.241,28.221$ & 0.02 \\
\hline Neonatal generalized tonic seizure & 1 & 9 & 11.836 & $1.466,95.526$ & 0.02 \\
\hline $\begin{array}{l}\text { Neonatal EEG }(n=34) \\
\text { abnormal background activity }\end{array}$ & $\begin{array}{l}n=17 \\
4\end{array}$ & $\begin{array}{l}\mathbf{n}=\mathbf{1 7} \\
11\end{array}$ & 5.958 & $1.332,26.662$ & 0.02 \\
\hline $\begin{array}{l}\text { Discharge from NICU with at least one } \\
\text { antiepileptic drug }\end{array}$ & 16 & 42 & 3.454 & $1.806,6.606$ & 0.000 \\
\hline Spastic bilateral (tetraparesis) & 42 & 66 & 2.986 & $1.535,5.808$ & 0.001 \\
\hline $\begin{array}{l}\text { Epileptiform discharge in the } 6^{\text {th }} \text { month EEC } \\
(n=53)\end{array}$ & $\begin{array}{l}\mathbf{n}=\mathbf{1 8} \\
3\end{array}$ & $\begin{array}{l}\mathbf{n}=\mathbf{3 5} \\
27\end{array}$ & 16.875 & $3.882,73.347$ & 0.000 \\
\hline MRI at one year of age & $n=102$ & $n=107$ & & & \\
\hline \multirow{3}{*}{$\begin{array}{l}\text { - Cerebral atrophy } \\
\text { - Cerebral abnormality } \\
\text { - Hydrocephalus }\end{array}$} & 11 & 25 & 4.545 & $1.437,14.378$ & 0.01 \\
\hline & 12 & 24 & 4 & $1.277,12.528$ & 0.01 \\
\hline & 9 & 22 & 4.889 & $1.482,16.128$ & 0.009 \\
\hline Mental retardation & 58 & 94 & 3.917 & $2.199,6.977$ & 0.000 \\
\hline Microcephaly & 32 & 70 & 3.828 & $2.212,6.627$ & 0.000 \\
\hline Visual problems & 13 & 32 & 2.948 & $1.456,5.969$ & 0.003 \\
\hline
\end{tabular}

MRI: Magnetic resonance imaging, EEG: Electroencephalography, NICU: Neonatal intensive care unit 
neonatal convulsions, focal clonic and generalized tonic neonatal seizures were found to increase the risk of epilepsy 6 and 12 times respectively. In the present study, we also found that the presence of abnormal background activity in the neonatal EEG increased the risk of epilepsy 6 times. However, there are no data on this subject in the literature. Our study showed that cases discharged from the NICU with antiepileptic medication was linked to an increased risk of epilepsy by 3.4 times. More interestingly, to the best of our knowledge, our study is the first to show this finding in the literature.

Spastic bilateral (tetraplegic) CP was the most common type in both groups, and its presence increased the risk of epilepsy by about three times compared to other CP types $(p=0.001)$. In addition, tetraplegic CP has been shown to be a risk factor for epilepsy in previous studies $(5,15,19)$. However, Singhi (14) reported that the rate of epilepsy was the highest in spastic hemiplegic patients. Although there was no significant difference in the background activity on EEG at six months between the two groups, we found a significant difference in terms of focal or generalized epileptic activity $(p=0.000)$. In addition, the presence of epileptic activity on EEG increased the risk of epilepsy by 16.875 times in patients with CP $(p=0.000)$. In epileptic cases, the median and mean age of seizure onset was 6 months and 21.4 months respectively. In most of the epileptic cases (62\%), recurrent seizures first occurred within the first year of life. A similar rate was previously reported in the literature as 49 to $79 \%$ $(14,15,19)$. However, seizure onset age may vary depending on the CP type. Carlsson et al. (5) reported a mean age of epilepsy onset in tetraplegic, diplegic and hemiplegic CP patients as 6 years, 1 year and 2.5 years respectively. In our study, the median epilepsy onset age was 3 months, 8.5 months, 24.5 months and 33 months in the patients with spastic bilateral (tetraplegic), spastic unilateral, spastic bilateral (diplegic) and dyskinetic type CP respectively. However, it did not reach statistical significance $(p=0.069)$. In the present study, the most common seizure type was generalized seizure (46.6\%), followed by focal and secondary generalized seizures (39\%). Infantile spasms were observed in $7.6 \%$ of epileptic patients. However, Gururaj et al. (19) reported that partial seizures were the most frequent seizures in their patients (39.3\%). Similar to our results, Singhi (14) found generalized tonicclonic seizures $(38.1 \%)$ to be the most frequent seizure type among their study population. In another study, Hadjipanayis et al. (22) reported typical and atypical absence seizures in their cases. West syndrome and Lennox-Gastaut syndrome were found in nine and two patients respectively. Kulak and Sobaniec (17) reported that Lennox-Gastaut syndrome developed in six patients with spastic tetraplegic and dyskinetic CP in their study. Furthermore, EEG recordings of the patients obtained in the final visit revealed a rate of epileptic activity of $79.7 \%$ in Group II. The most frequent finding was focal/multifocal epileptic activity (55.9\%). This ratio varied between 66 and $92.7 \%$ in previous studies $(14,17)$. However, in these studies, generalized activity was found to be more common. In one study, epileptic activity was found to be a significant and independent risk factor affecting the prognosis of epilepsy (20). In Group II, antiepileptic therapy was discontinued in $7.6 \%$ of the cases and the remaining cases continued to use at least one antiepileptic drug. Seizure control with single or multiple antiepileptic drugs were $47.5 \%$ and $24.6 \%$, respectively. The rate of drug-resistant epilepsy was $20.3 \%$. Previous studies also reported a similar rate as $35.7-45 \%(17,19)$. In the present study, cranial MRI revealed abnormal findings in $86.3 \%$ and $93.5 \%$ in Group I and Group II, respectively. Gururaj et al. (19) found similar rates of $94 \%$ and $97 \%$. The presence of cerebral atrophy, cerebral abnormality and hydrocephalus were significantly associated with the increased epilepsy development $(p<0.01)$. In previous studies, abnormal cranial MRI findings, mainly cerebral atrophy, were more frequent in $\mathrm{CP}+$ epilepsy group than in the CP group $(15,19)$. In the current study, we found that microcephaly also increased the risk of epilepsy by 3.8 times in CP patients $(p=0.000)$. In contrast, Zelnik et al. (15) found that the ratio of microcephaly did not differ among the $\mathrm{CP}$ and $\mathrm{CP}+$ epilepsy patients. Similar to the present study, developmental delay and mental retardation were also found to be more frequent in patients with CP+ epilepsy, compared to those with CP $(15,19,21)$. In one study, Mert et al. (20) reported that mental retardation was a risk factor for epilepsy in CP cases. Singhi (14) found no significant difference between the $\mathrm{CP}$ and $\mathrm{CP}+$ epilepsy groups in terms of social quotient, although seizures were more frequent and difficult to manage in the patients with mental retardation. Finally, we found that visual problems significantly increased the risk of epilepsy in $\mathrm{CP}$ cases, although there are no data in the literature on the association between visual problems and increased risk of epilepsy.

\section{Study Limitations}

This is a retrospective study. Information was obtained from families and medical records.

\section{Conclusion}

The presence of neonatal seizures in patients with $C P$, the use of antiepileptic drugs at discharge from the NICU, the presence of bilateral spastic (tetraplegic) CP, abnormal background activity on neonatal EEG, the presence of epileptic activity on the sixth-month EEG, the presence of cerebral atrophy, hydrocephalus and cerebral abnormality on cranial MRI, the presence of associated problems such as visual deficits, microcephaly and mental retardation are significant risk factors for the development of epilepsy in $\mathrm{CP}$ cases. Therefore, patients with these risk factors should be closely monitored in order to provide timely diagnosis and proper treatment. 


\section{Acknowledgements}

We thank Timur Köse for the statistical analysis of the study.

Ethics

Ethics Committee Approval: The study was approved by the Ege University Local Ethics Committee (approval number: 16-3/3).

Informed Consent: Consent form was filled out by parents of patient.

Peer-review: Externally peer-reviewed.

\section{Authorship Contributions}

Concept: S.G., G.A. H.T, Design: S.G, F.G., Data Collection and Processing: F.G, H.M.S., Analysis and Interpretation: S.G. H.T. G.A, Literature Search: F.G. S.Y. H.M.S, Writing: F.G., S.Y. S.G.

Conflict of Interest: The authors have stated that they have no interests which might be perceived as posing a conflict

Financial Disclosure: The authors declared that this study received no financial support.

\section{References}

1. Hagberg B, Hagberg G, Olow I, van Wendt L. The changing panorama of cerebral palsy in Sweden. VII. Prevalence and origin in the birth year period 1987-90. Acta Paediatr 1996;85:954-60.

2. Serdaroglu A, Cansu A, Ozkan S, Tezcan S. Prevalence of cerebral palsy in Turkish children between the ages of 2 and 16 years. Dev Med Child Neurol 2006;48:413-6.

3. Nissenkorn A, Weintraub $S$, Sadeh $M$, Lerman-Sagie $T$. Lissencephaly associated with congenital hypomyelinating and axonal neuropathy. Pediatric Neurol 1998;19:313-6.

4. Wallace SJ. Epilepsy in cerebral palsy. Dev Med Child Neurol 2001;43:713-7.

5. Carlsson M, Hagberg G, Olsson I. Clinical and aetiological aspects of epilepsy in children with cerebral palsy. Dev Med Child Neurol 2003;45:371-6.

6. Rosenbaum P, Paneth $\mathrm{N}$, Leviton $\mathrm{A}$, et al. A report: The Definition and Classification of Cerebral Palsy April 2006. Dev Med Child Neurol Suppl 2007;109:8-14.

7. WHO Expert Committee: Physical Status: The Use and Interpretation of Anthropometry: Report of a WHO Expert Committee. Geneva, World Health Organization, 1995.
8. Volpe IJ. Neonatal seizures: Current Concepts and Revised Classification. Pediatrics 1989;84:422-8.

9. Surveillance of Cerebral Palsy in Europe. Surveillance of cerebral palsy in Europe: a collaboration of cerebral palsy surveys and registers. Surveillance of Cerebral Palsy in Europe (SCPE). Dev Med Child Neurol 2000;42:816-24.

10. Mutch L, Alberman E, Hagberg B, Kodama K, Perat MV. Cerebral palsy epidemiology: where are we now and where are we going? Dev Med Child Neurol 1992;34:547-51.

11. No authors listed. Guidelines for epidemiologic studies on epilepsy. Commission on Epidemiology and Prognosis, International League Against Epilepsy. Epilepsia 1993;34:592-6.

12. Berg AT, Berkovic SF, Brodie MJ, et al. Revised terminology and concepts for organization of seizures and epilepsies: report of the ILAE Commission on Classification and Terminology, 20052009 Epilepsia 2010;51:676-85.

13. Cooper MS, Mackay MT, Fahey M, et al. Seizures in Children With Cerebral Palsy and White Matter Injury. Pediatrics 2017;139:1-11.

14. Singhi P. The child with cerebral palsy-clinical consideration and management. Indian / Pediatr 2001;68:531-6.

15. Zelnik N, Konopnicki M, Bennett-Back O, Castel-Deutsch T, Tirosh E. Risk factors for epilepsy in children with cerebral palsy. Eur J Paediatr Neurol 2010;14:67-72.

16. Gajewska E, Sobieska M, Samborski W. Associations between Manual Abilities, Gross Motor Function, Epilepsy, and Mental Capacity in Children with Cerebral Palsy. Iran / Child Neurol 2014;8:45-52.

17. Kulak W, Sobaniec W. Risk factors and prognosis of epilepsy in children with cerebral palsy in North-eastern Poland. Brain Dev 2003;27:499-506

18. Sellier E, Uldall P, Calado E, et al. Epilepsy and cerebral palsy: characteristic and trends in children born in 1976-1998. Eur ) Paediatr Neurol 2012;16:48-55.

19. Gururaj AK, Sztriha L, Bener A, Dawadou A, Eapen V. Epilepsy in children with cerebral palsy. Seizure 2003;12:110-4.

20. Mert GG, Incecik F, Altunbasak S, et al. Factors affecting epilepsy development and epilepsy prognosis in cerebral palsy. Pediatr Neurol 2011;45:89-94.

21. El-Tallawy HN, Farghaly WM, Shehata GA, Badry R, Rageh TA. Epileptic and cognitive changes in children with cerebral palsy: an Egyptian study. Neuropsychiatr Dis Treat 2014;10:971-5.

22. Hadjipanayis A, Hadjichristodoulou C, Yourokos S. Epilepsy in patients with cerebral palsy. Dev Med Child Neurol 1997;39:65963. 